\title{
Prevalence and Clinical Significance of Subclinical Hypothyroidism in Diabetic Peripheral Neuropathy
}

\author{
Mahmoud A Allam' \\ Youssef A Nassar' \\ Hosameldeen S Shabana (D) \\ Sadek Mostafa' \\ Farag Khalil' \\ Hendawy Zidan' \\ Mohammed Abo-Ghebsha ${ }^{2}$ \\ Amir Abdelghaffar ${ }^{3}$ \\ Ahmed Essmat ${ }^{3}$ \\ Essam Elmahdi ${ }^{4}$ \\ 'Department of Internal Medicine, \\ Faculty of Medicine, Al-Azhar University, \\ Cairo, Egypt; ${ }^{2}$ Department of Clinical \\ Pathology, Faculty of Medicine, Al-Azhar \\ University, Cairo, Egypt; ${ }^{3}$ Department of \\ Neurology, Faculty of Medicine, Al-Azhar \\ University, Cairo, Egypt; ${ }^{4}$ Department of \\ Internal Medicine, Faculty of Medicine, \\ Mansoura University, Mansoura, Egypt
}

Correspondence: Mahmoud A Allam Department of Internal Medicine, Faculty of Medicine, Al-Azhar University, Cairo, I 1884, Egypt

Tel +20222602687

Fax +20224020184

Email dr.mahmoudallam75@gmail.com
Background and Aim: Diabetic peripheral neuropathy (DPN) is one of the most common and disabling complications of DM. Many studies documented the prevalence of clinical and subclinical hypothyroidism $(\mathrm{SCH})$ in diabetic patients but not in the particular group of patients with DPN. The present study aimed to determine the prevalence of SCH in DPN patients and to evaluate its association with severity of DPN.

Patients and Methods: The present cross-sectional study was conducted on 300 consecutive patients with DPN. The clinical manifestations of DPN were documented according to the validated Arabic version of the Michigan Neuropathy Screening Instrument. Severity of DPN was categorized into mild (6-8 points), moderate (9-11 points) or severe (12+ points) according to the Toronto Clinical Scoring System. All patients were submitted to careful history-taking and full clinical and neurological examination. Patients were diagnosed with $\mathrm{SCH}$ if they had TSH level above the upper limit of the normal reference range in association with normal free thyroxine (FT4) level.

Results: $\mathrm{SCH}$ was prevalent in 53 patients $(17.7 \%$, 95\% CI: $13.5 \%-22.5 \%)$. Patients with SCH had significantly higher frequency of severe DPN $(52.8 \%$ versus $28.3 \%, p=0.003)$. It was also shown that patients with $\mathrm{SCH}$ had significantly higher $\mathrm{HbA} 1 \mathrm{c}(8.4 \pm 1.0$ versus 7.3 $\pm 1.2 \%, p<0.001)$ and HOMA-IR $(3.7 \pm 0.8$ versus $2.7 \pm 0.9, p<0.001)$ when compared with patients without $\mathrm{SCH}$. Logistic regression analysis identified patients' age [OR (95\% CI): 1.06 (1.03-1.08), $p<0.001$ ], HbA1c [OR (95\% CI): $2.2(1.7-2.9), p<0.001]$ and SCH [OR (95\% CI): 7.7 (3.6-15.5), $p<0.001]$ as independent predictors of DPN severity.

Conclusion: The present study showed that SCH is highly prevalent in DPN patients and is independently related to its severity.

Keywords: diabetes mellitus, diabetic peripheral neuropathy, subclinical hypothyroidism, thyroid hormones, thyroid dysfunction

\section{Introduction}

Diabetes mellitus (DM) is one of the most significant global health epidemics, with nearly 1 in 11 adults worldwide having DM, mostly of type 2 . The huge burden of the disease is related to long-term and devastating complications and the wide range of associated comorbidities. ${ }^{1}$ Among these morbidities, thyroid dysfunction is frequently reported in association with DM. On the other hand, DM is fairly common in patients with thyroid dysfunction. ${ }^{2}$ Many studies documented the prevalence of clinical and subclinical hypothyroidism $(\mathrm{SCH})$ in diabetic patients ${ }^{3-6}$ and its relation to diabetic nephropathy. ${ }^{7,8}$

Diabetic peripheral neuropathy (DPN) is one of the most common and disabling complications of DM. DPN can present in acute or chronic forms affecting all 
segments of peripheral nerves from the originating root to the distal axon. ${ }^{9}$ Clinically, DPN is manifested by numbness, paresthesias and burning pain that proximally progresses across feet and hand in a stocking-glove distribution. $^{10}$

The pathogenesis of DPN is quite complex. Suggested pathogenic mechanisms include mitochondrial dysfunction ${ }^{11}$ and Schwann cells apoptosis ${ }^{12}$ induced by hyperglycemia, dyslipidemia, insulin resistance, oxidative stress and the chronic inflammatory state related to $\mathrm{DM}^{13}$

In spite of the marked progress achieved in management of DPN, the efficacy of available treatment options is far from optimal, and no disease-modifying drug exists. This is largely attributed to the fact that current treatment recommendations do not address the specific underlying pathogenic mechanisms. Thorough understanding of these mechanisms is essential for making significant progress in this field. ${ }^{14,15}$

The present study aimed to determine the prevalence of $\mathrm{SCH}$ in diabetic patients with DPN and to discover its relation to the clinical severity of the disease.

\section{Methodology}

The present cross-sectional study was conducted at the outpatient diabetes unit, Al-Azhar University Hospitals during the period from January 2019 through February 2020. The study protocol was approved by the ethical committee of Al-Azhar University Faculty of Medicine, and written informed consent was obtained from all participants in accordance with the Declaration of Helsinki on clinical research involving human subjects.

The study included 300 consecutive patients with DPN. Diagnosis of DPN was established on the basis of nerve conduction studies (abnormal nerve conduction velocity of the sural or peroneal nerves) together with symptoms and signs of DPN. The clinical manifestations of DPN were documented according to the validated Arabic version of the Michigan Neuropathy Screening Instrument. The instrument includes a 15-item yes/no questionnaire in addition to physical examination. ${ }^{16,17}$ Patients were excluded if they had known thyroid disease or were receiving treatment that can modify thyroid function.

Severity of DPN was categorized into mild (6-8 points), moderate (9-11 points) or severe $(12+$ points) according to the Toronto Clinical Scoring
System (TCSS). TCSS is a validated peripheral neuropathy grading system that combines neurological symptoms scores, reflexes scores and sensory test scores. ${ }^{18}$

All patients had careful history-taking as well as full clinical and neurological examination. Laboratory work-up included complete blood count, fasting and postprandial blood glucose and fasting insulin levels. Insulin resistance was calculated using the Homeostatic Model Assessment of Insulin Resistance (HOMA-IR) using the equation: HOMA-IR=fasting insulin $(\mathrm{U} / \mathrm{L}) \times$ fasting glucose $(\mathrm{mg} /$ dL)/405. Glycemic control was assessed using HbA1c levels. Patients were diagnosed with $\mathrm{SCH}$ if they had a TSH level above the upper limit of the normal reference range in association with normal free thyroxine (FT4) level. The normal reference ranges of thyroid functions were: $0.27-4.5 \mu \mathrm{IU} / \mathrm{mL}$ for $\mathrm{TSH}$ and $0.93-1.7 \mathrm{ng} / \mathrm{dL}$ for FT4.

Data obtained from the present study were expressed as number and percent or mean and standard deviation (SD). Prevalence was expressed as proportion and 95\% CI. Categorical data were compared using Fisher's exact test or chi-square test, while numerical data were compared using $t$-test. Logistic regression analysis was used to identify predictors of DPN severity. $P$ value less than 0.05 was considered statistically significant. All statistical operations were processed using SPSS 25 (IBM, USA).

\section{Results}

Throughout the study period, there were 329 patients who fulfilled the clinical criteria of DPN. However, 29 patients were excluded. They comprised patients with other thyroid diseases $(n=12)$ or those receiving medications that can affect thyroid functions (eg amiodarone, carbamazepine, etc.) $(n=17)$. Finally, the study included 300 patients with DPN. There were 127 males (42.3\%) and 173 females $(57.7 \%)$ with an age of $52.9 \pm 12.0$ years. $\mathrm{SCH}$ was prevalent in 53 patients $(17.7 \%, 95 \%$ CI: $13.5 \%-22.5 \%$ ). Comparison between patients with $\mathrm{SCH}$ and patients without revealed that patients with SCH had significantly higher frequency of severe DPN (52.8\% versus $28.3 \%, p=0.003$ ) (Figure 1). It was also shown that patients with $\mathrm{SCH}$ had significantly higher HbA1c $(8.4 \pm 1.0$ versus $7.3 \pm 1.2 \%, p<0.001$; Figure 2$)$ and HOMA-IR $(3.7 \pm 0.8$ versus $2.7 \pm 0.9, p<0.001$; Figure 3) when compared with patients without $\mathrm{SCH}$ (Table 1). 


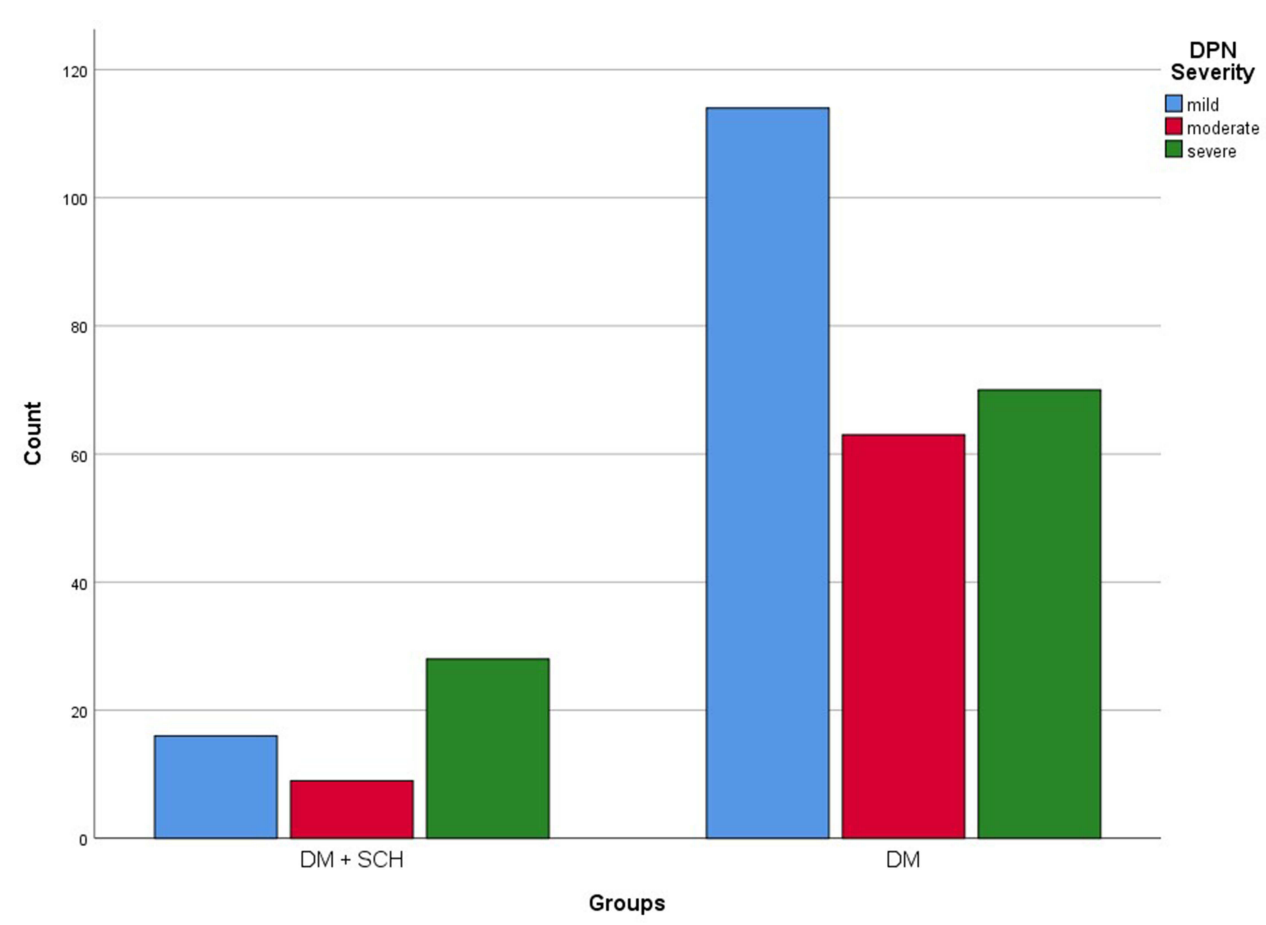

Figure I DPN severity in patients with and without $\mathrm{SCH}$.

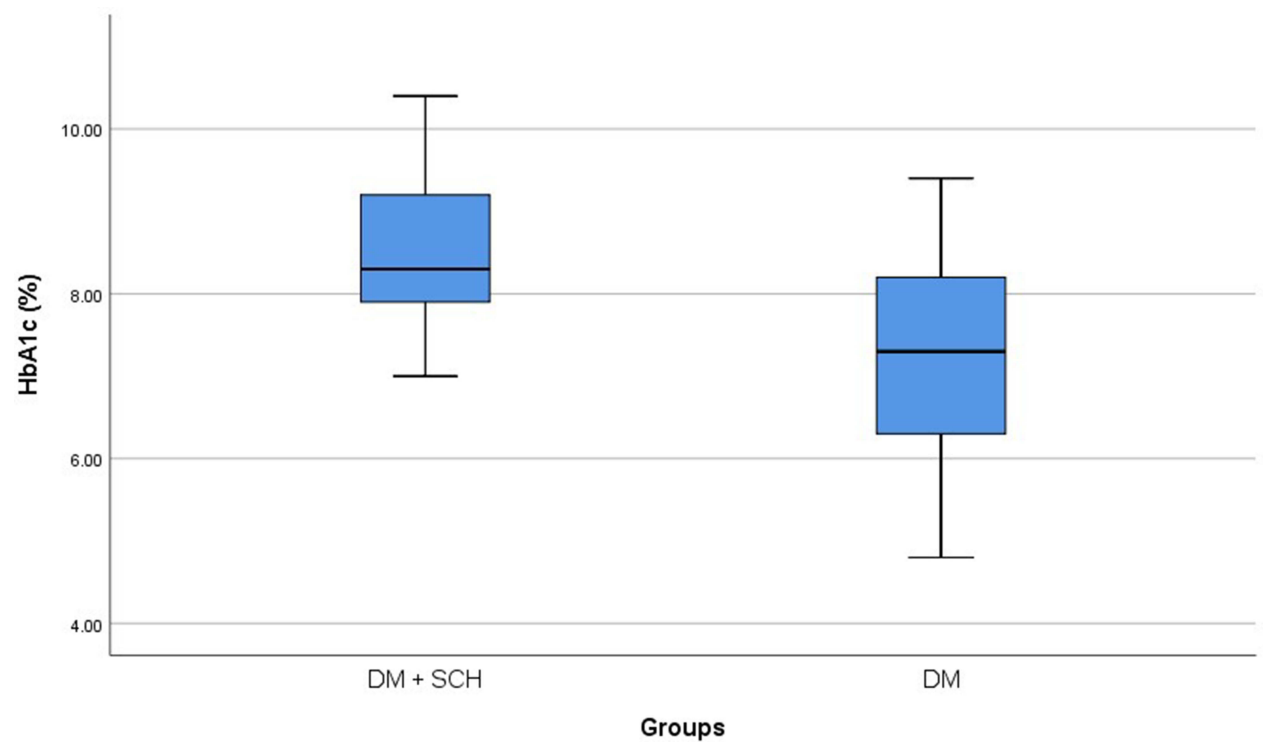

Figure 2 Glycemic control in patients with and without $\mathrm{SCH}$.

According to DPN severity, patients were classified into those with severe DPN $(n=98)$ and non-severe (mild/ moderate) DPN ( $n=202)$. Logistic regression analysis identified patients' age [OR (95\% CI): 1.06 (1.03-1.08), $p<0.001$ ], HbAlc [OR (95\% CI): $2.2(1.7-2.9), p<0.001]$ and $\mathrm{SCH}$ [OR $(95 \% \mathrm{CI}): 7.7(3.6-15.5), p<0.001]$ as independent predictors of DPN severity (Table 2 ).

\section{Discussion}

The present study assessed the prevalence of SCH in 300 consecutive patients with DPN. The study found that 53 patients $(17.7 \%)$ had $\mathrm{SCH}$. The prevalence of $\mathrm{SCH}$ was previously determined in patients with various diabetic complications including diabetic nephropathy ${ }^{8,19}$ and retinopathy. ${ }^{20-22}$ In the general 


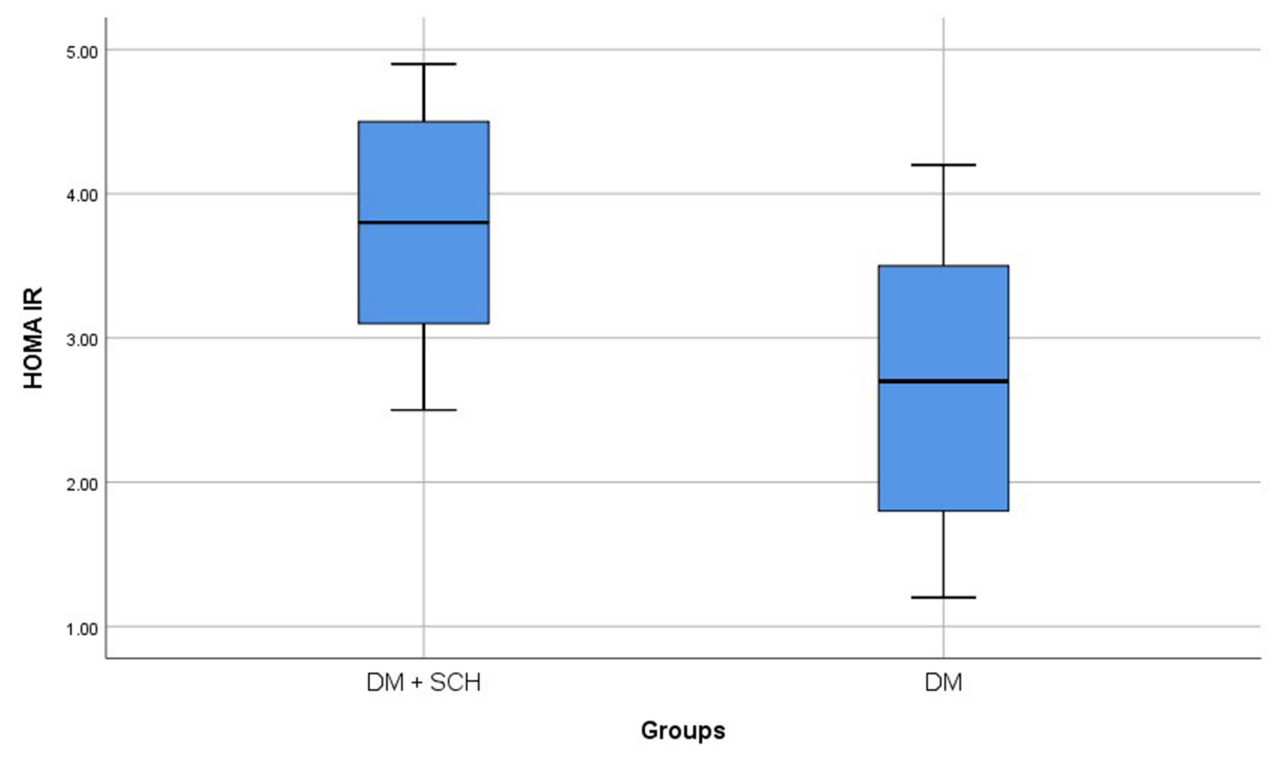

Figure 3 Insulin resistance in patients with and without $\mathrm{SCH}$.

population, one study reported $\mathrm{SCH}$ in $11.3 \%$ of the included subjects. ${ }^{23}$

In our study, patients with $\mathrm{SCH}$ had significantly higher frequency of cases with severe DPN when compared with patients without SCH. Multivariate analysis confirmed SCH as an independent predictor of DPN severity. The relation between $\mathrm{SCH}$ and DPN was previously reported in a Chinese cohort. ${ }^{24}$

The contribution of SCH to the pathogenesis of DPN can be explained by multiple mechanisms. First, $\mathrm{SCH}$ has been shown to increase oxidative stress. ${ }^{25,26}$ Augmented oxidative stress in turn is a well-known mechanism involved in the development of DPN as evidenced by experimental and clinical studies. ${ }^{27-29}$

Second, SCH has also been found to be associated with pronounced inflammatory state. ${ }^{30-33}$ The role of proinflammatory state in the pathogenesis of DPN is welldocumented. ${ }^{34,35}$

A third mechanism that may interrelate $\mathrm{SCH}$ and DPN is dyslipidemia which was found to be associated with $\mathrm{SCH}^{36,37}$ and is considered as a risk factor for DPN. ${ }^{38-40}$

In addition, the current study recognized an association between $\mathrm{SCH}$ and poor glycemic control. These results are supported by the conclusions of Cho et $\mathrm{al}^{41}$ who noted that diabetic patients with poor glycemic control have higher risk for development of $\mathrm{SCH}$.

Moreover, we found that patients with $\mathrm{SCH}$ had significantly higher HOMA-IR levels. Such a relationship was previously reported in other diabetic patients. ${ }^{20}$ In fact, even in the general population, Kocatürk et $\mathrm{al}^{42}$ found a significant association between insulin resistance, impaired $\beta$-cell function and increased TSH levels.

Our study suggests that $\mathrm{SCH}$ aggravates the pathogenic mechanisms related to DM and DPN that are consequences of the metabolic derangements induced by insulin resistance and hyperglycemia. It may be beneficial to screen all diabetic patients for $\mathrm{SCH}$ to prevent or limit significant neuropathic complications. In fact, the British and American Associations recommend screening of diabetic patients for thyroid abnormalities. However, the British recommendations restrict screening to the time of diagnosis ${ }^{43}$ while American guidelines ${ }^{44}$ recommend that patients older than 35 years should have thyroid assessments every 5 years. Probably, our findings are supportive of the American recommendations. Interestingly, the European Thyroid Association suggests that L-thyroxine may be tried if onset of $\mathrm{SCH}$ was associated with worsening of glycemic control. ${ }^{45}$

In conclusion, the present study showed that $\mathrm{SCH}$ is prevalent in DPN patients and suggests that $\mathrm{SCH}$ is independently related to its severity. These conclusions are limited by the cross-sectional study design. Longitudinal follow-up of patients would better determine onset and deterioration of $\mathrm{SCH}$ and its clinical impact. In addition, adding a control diabetic group without DPN would add to the study value. This may be more conclusive regarding the association between 
Table I Comparison Between Patients with SCH and Patients Without Regarding the Clinical and Laboratory Data

\begin{tabular}{|c|c|c|c|c|}
\hline & All Patients $\mathbf{N}=\mathbf{3 0 0}$ & SCH +ve $n=53$ & SCH -ve $n=247$ & $P$ value \\
\hline Age (years) mean \pm SD & $52.9 \pm 12.0$ & $52.3 \pm 11.7$ & $53.0 \pm 12.1$ & 0.69 \\
\hline Male/female $n$ & $127 / 173$ & $20 / 33$ & $107 / 140$ & 0.46 \\
\hline BMI $\left(\mathrm{kg} / \mathrm{m}^{2}\right)$ mean \pm SD & $33.0 \pm 4.2$ & $33.8 \pm 3.9$ & $32.8 \pm 4.3$ & 0.12 \\
\hline Duration of DM (years) mean \pm SD & $9.4 \pm 8.7$ & $10.6 \pm 9.8$ & $9.2 \pm 8.5$ & 0.26 \\
\hline \multicolumn{5}{|l|}{ Associated comorbidities $n(\%)$} \\
\hline Smoking & $64(21.3)$ & I5 (28.3) & $49(19.8)$ & 0.17 \\
\hline Hypertension & $213(7 \mid .0)$ & $34(64.2)$ & $179(72.5)$ & 0.23 \\
\hline IHD & $39(13.0)$ & $7(13.2)$ & $32(13.0)$ & 0.96 \\
\hline Stroke & $25(8.3)$ & $6(11.3)$ & $19(7.7)$ & 0.39 \\
\hline \multicolumn{5}{|l|}{ Severity of DPN n (\%) } \\
\hline Mild & $130(43.3)$ & $16(30.2)$ & II 4 (46.2) & 0.003 \\
\hline Moderate & $72(24.0)$ & $9(I 7.0)$ & $63(25.5)$ & \\
\hline Severe & $98(32.7)$ & $28(52.8)$ & $70(28.3)$ & \\
\hline \multicolumn{5}{|l|}{ Laboratory findings mean $\pm S D$} \\
\hline $\mathrm{FBS}(\mathrm{mg} / \mathrm{dL})$ & $133.8 \pm 21.2$ & $136.8 \pm 14.9$ & $131.6 \pm 21.7$ & 0.097 \\
\hline PPBS (mg/dL) & $189.9 \pm 41.5$ & $193.2 \pm 49.2$ & $189.2 \pm 39.7$ & 0.53 \\
\hline $\mathrm{Hb}(\mathrm{g} / \mathrm{dL})$ & $11.6 \pm 2.0$ & $11.3 \pm 1.1$ & $11.7 \pm 2.1$ & 0.083 \\
\hline $\operatorname{TLC}\left(\times 10^{3} / \mathrm{mL}\right)$ & $7.8 \pm 1.9$ & $8.1 \pm 1.6$ & $7.7 \pm 2.0$ & 0.14 \\
\hline Platelets $\left(\times 10^{3} / \mathrm{mL}\right)$ & $265.4 \pm 72.8$ & $282.0 \pm 87.4$ & $261.8 \pm 69.0$ & 0.12 \\
\hline Cholesterol (mg/dL) & $222.3 \pm 41.5$ & $230.3 \pm 34.6$ & $220.6 \pm 42.8$ & 0.13 \\
\hline Triglycerides (mg/dL) & $218.2 \pm 88.0$ & $233.5 \pm 84.2$ & $217.1 \pm 88.9$ & 0.63 \\
\hline $\mathrm{HDL}(\mathrm{mg} / \mathrm{dL})$ & $43.7 \pm 10.1$ & $41.9 \pm 9.4$ & $44.1 \pm 10.2$ & 0.15 \\
\hline LDL (mg/dL) & $129.7 \pm 44.8$ & $135.3 \pm 4 \mid .8$ & $128.6 \pm 45.5$ & 0.32 \\
\hline HbAlc (\%) & $7.5 \pm 1.2$ & $8.4 \pm 1.0$ & $7.3 \pm 1.2$ & $<0.001$ \\
\hline HOMA-IR & $2.8 \pm 1.0$ & $3.7 \pm 0.8$ & $2.7 \pm 0.9$ & $<0.001$ \\
\hline
\end{tabular}

Abbreviations: BMI, body mass index; FBS, fasting blood glucose; FT3, free triiodothyronine; FT4, free thyroxine; HDL, high-density lipoprotein; IHD, ischemic heart disease; LDL, low-density lipoprotein; PPBS, post-prandial blood sugar; SCH +ve, patients with subclinical hypothyroidism; SCH -ve, patients without subclinical hypothyroidism.

Table 2 Predictors of Severe DPN in the Studied Patients

\begin{tabular}{|l|c|c|c|c|c|c|}
\hline \multirow{2}{*}{} & \multicolumn{3}{|c|}{ Univariate Analysis } & \multicolumn{3}{c|}{ Multivariate Analysis } \\
\cline { 2 - 7 } & OR & $\mathbf{9 5 \%} \mathbf{C l}$ & $\mathbf{P}$ & $\mathbf{O R}$ & $\mathbf{9 5 \%} \mathbf{C l}$ & $\mathbf{P}$ \\
\hline Age & 1.06 & $1.03-1.08$ & $<0.001$ & 1.06 & $1.03-1.08$ & $<0.001$ \\
Sex & 0.58 & $0.35-0.96$ & 0.035 & 1.3 & $0.73-2.3$ & 0.37 \\
HbAIc & 1.8 & $1.4-2.2$ & $<0.001$ & 2.2 & $1.7-2.9$ & $<0.001$ \\
HOMA-IR & 0.79 & $0.61-1.02$ & 0.071 & - & - & - \\
SCH & 2.8 & $1.5-5.2$ & 0.001 & 7.7 & $3.6-15.5$ & $<0.001$ \\
\hline
\end{tabular}

DPN development and SCH. Longitudinal studies with a larger sample size are recommended to allow generalization of our conclusions.

\section{Data Sharing Statement}

The datasets used and analyzed during the current study are available from the corresponding author on reasonable request.

\section{Disclosure}

The authors declare no conflicts of interest, financial or otherwise, in this work.

\section{References}

1. Zheng Y, Ley SH, Hu FB. Global aetiology and epidemiology of type 2 diabetes mellitus and its complications. Nat Rev Endocrinol. 2018;14 (2):88-98. PMID: 29219149. doi:10.1038/nrendo.2017.151 
2. Biondi B, Kahaly GJ, Robertson RP. Thyroid dysfunction and diabetes mellitus: two closely associated disorders. Endocr Rev. 2019;40 (3):789-824. PMID: 30649221; PMCID: PMC6507635. doi:10.1210/ er.2018-00163

3. Song F, Bao C, Deng M, et al. The prevalence and determinants of hypothyroidism in hospitalized patients with type 2 diabetes mellitus. Endocrine. 2017;55(1):179-185. PMID: 27605039. doi:10.1007/ s12020-016-1095-2

4. Alsolami AA, Alshali KZ, Albeshri MA, et al. Association between type 2 diabetes mellitus and hypothyroidism: a case-control study. Int $J$ Gen Med. 2018;11:457-461. PMID: 30584348; PMCID: PMC6287518. doi:10.2147/IJGM.S179205

5. Nair A, Jayakumari C, Jabbar PK, et al. Prevalence and associations of hypothyroidism in Indian patients with type 2 diabetes mellitus. J Thyroid Res. 2018;2018:5386129. PMID: 30174822; PMCID: PMC6106958. doi:10.1155/2018/5386129

6. Talwalkar P, Deshmukh V, Bhole M. Prevalence of hypothyroidism in patients with type 2 diabetes mellitus and hypertension in India: a cross-sectional observational study. Diabetes Metab Syndr Obes. 2019;12:369-376. PMID: 30936734; PMCID: PMC6431000. doi:10.2147/DMSO.S181470

7. Furukawa S, Yamamoto S, Todo Y, et al. Association between subclinical hypothyroidism and diabetic nephropathy in patients with type 2 diabetes mellitus. Endocr J. 2014;61(10):1011-1018. PMID: 25100149. doi:10.1507/endocrj.ej14-0206

8. Xie J, Wang X, Zhang Y, Li H, Xu Y, Zheng D. The longitudinal effect of subclinical hypothyroidism on urine microalbumin-to-urine creatinine ratio in patients with type 2 diabetes mellitus. BMC Endocr Disord. 2019;19(1):84. PMID: 31382952; PMCID: PMC6683563. doi:10.1186/s12902-019-0405-0

9. Juster-Switlyk K, Smith AG. Updates in diabetic peripheral neuropathy. F1000Res. 2016;25:5. PMID: 27158461; PMCID: PMC4847561. doi:10.12688/f1000research.7898.1

10. Snyder MJ, Gibbs LM, Lindsay TJ. Treating painful diabetic peripheral neuropathy: an update. Am Fam Physician. 2016;94(3):227-234. PMID: 27479625 .

11. Chandrasekaran K, Anjaneyulu M, Choi J, et al. Role of mitochondria in diabetic peripheral neuropathy: influencing the NAD+dependent SIRT1-PGC-1 $\alpha$-TFAM pathway. Int Rev Neurobiol. 2019;145:177-209. PMID: 31208524; PMCID: PMC6590704. doi:10.1016/bs.irn.2019.04.002

12. Liu YP, Shao SJ, Guo HD. Schwann cells apoptosis is induced by high glucose in diabetic peripheral neuropathy. Life Sci. 2020;248:117459. PMID: 32092332. doi:10.1016/j.lfs.2020.117459

13. Stino AM, Rumora AE, Kim B, Feldman EL. Evolving concepts on the role of dyslipidemia, bioenergetics, and inflammation in the pathogenesis and treatment of diabetic peripheral neuropathy. $J$ Peripher Nerv Syst. 2020;25(2):76-84. PMID: 32412144; PMCID: PMC7375363. doi:10.1111/jns. 12387

14. Selvarajah D, Kar D, Khunti K, et al. Diabetic peripheral neuropathy: advances in diagnosis and strategies for screening and early intervention. Lancet Diabetes Endocrinol. 2019;7(12):938-948. PMID: 31624024. doi:10.1016/S2213-8587(19)30081-6

15. Khdour MR. Treatment of diabetic peripheral neuropathy: a review. $J$ Pharm Pharmacol. 2020;72(7):863-872. PMID: 32067247. doi:10.1111/jphp.13241

16. Feldman EL, Stevens MJ, Thomas PK, Brown MB, Canal N, Greene DA. A practical two-step quantitative clinical and electrophysiological assessment for the diagnosis and staging of diabetic neuropathy. Diabetes Care. 1994;17(11):1281-1289. PMID: 7821 168. doi:10.2337/diacare.17.11.1281

17. Mohammad MT, Muhaidat J, Momani MS, et al. Translation and psychometric properties of the Arabic version of Michigan neuropathy screening instrument in type 2 diabetes. $J$ Diabetes Res. 2019;2019:2673105. PMID: 31049355; PMCID: PMC6462346. doi:10.1155/2019/2673105
18. Perkins BA, Olaleye D, Zinman B, Bril V. Simple screening tests for peripheral neuropathy in the diabetes clinic. Diabetes Care. 2001;24 (2):250-256. PMID: 11213874. doi:10.2337/diacare.24.2.250

19. Mansournia N, Riyahi S, Tofangchiha S, et al. Subclinical hypothyroidism and diabetic nephropathy in Iranian patients with type 2 diabetes. $J$ Endocrinol Invest. 2017;40(3):289-295. PMID: 27738906. doi:10.1007/s40618-016-0560-3

20. Kim BY, Kim CH, Jung CH, Mok JO, Suh KI, Kang SK. Association between subclinical hypothyroidism and severe diabetic retinopathy in Korean patients with type 2 diabetes. Endocr J. 2011;58 (12):1065-1070. PMID: 21931224. doi:10.1507/endocrj.ej11-0199

21. Ramis JN, Artigas CF, Santiago MA, Mañes FJ, Canonge RS, Comas LM. Is there a relationship between TSH levels and diabetic retinopathy in the Caucasian population? Diabetes Res Clin Pract. 2012;97(3):e45-e47. PMID: 22717499. doi:10.1016/j.diabres.2012. 05.015

22. Wu J, Yue S, Geng J, et al. Relationship between diabetic retinopathy and subclinical hypothyroidism: a meta-analysis. Sci Rep. 2015;5:12212. PMID: 26193340; PMCID: PMC4507396. doi:10. 1038/srep12212

23. Deshmukh V, Behl A, Iyer V, Joshi H, Dholye JP, Varthakavi PK. Prevalence, clinical and biochemical profile of subclinical hypothyroidism in normal population in Mumbai. Indian J Endocrinol Metab. 2013;17(3):454-459. PMID: 23869302; PMCID: PMC3712376. doi: $10.4103 / 2230-8210.111641$

24. Zhao W, Zeng H, Zhang X, et al. A high thyroid stimulating hormone level is associated with diabetic peripheral neuropathy in type 2 diabetes patients. Diabetes Res Clin Pract. 2016;115:122-129. PMID: 26822260. doi:10.1016/j.diabres.2016.01.018

25. Cheserek MJ, Wu GR, Ntazinda A, Shi YH, Shen LY, Le GW. Association between thyroid hormones, lipids and oxidative stress markers in subclinical hypothyroidism. $J$ Med Biochem. 2015;34 (3):323-331. PMID: 28356843; PMCID: PMC4922350. doi:10.24 78/jomb-2014-0044

26. Aydogdu A, Karakas EY, Erkus E, et al. Epicardial fat thickness and oxidative stress parameters in patients with subclinical hypothyroidism. Arch Med Sci. 2017;13(2):383-389. PMID: 28261292; PMCID: PMC5332468. doi:10.5114/aoms.2017.65479

27. Etienne I, Magalhães LVB, Cardoso SA, et al. Oxidative stress markers in cognitively intact patients with diabetic neuropathy. Brain Res Bull. 2019;150:196-200. PMID: 31175898. doi:10.1016/ j.brainresbull.2019.06.001

28. Mallet ML, Hadjivassiliou M, Sarrigiannis PG, Zis P. The role of oxidative stress in peripheral neuropathy. $J$ Mol Neurosci. 2020;70(7):1009-1017. PMID: 32103400. doi:10.1007/s12031$020-01495-x$

29. Pang L, Lian X, Liu H, et al. Understanding diabetic neuropathy: focus on oxidative stress. Oxid Med Cell Longev. 2020;2020:9524635. PMID: 32832011; PMCID: PMC7422494. doi:10.1155/2020/9524635

30. Shojaei Nik MH, Darabi M, Ziaee A, Hajmanoochehri F. Serum phospholipase A2-IIA, hs-CRP, and lipids in women with subclinical hypothyroidism. Int J Endocrinol Metab. 2014;12(3):e16967. PMID: 25237323; PMCID: PMC4166036. doi:10.5812/ijem.16967

31. Gupta G, Sharma P, Kumar P, Itagappa M. Study on subclinical hypothyroidism and its association with various inflammatory markers. J Clin Diagn Res. 2015;9(11):BC04-BC06. PMID: 2667 4140; PMCID: PMC4668398. doi:10.7860/JCDR/2015/14640.6806

32. Stratigou T, Dalamaga M, Antonakos G, et al. Hyperirisinemia is independently associated with subclinical hypothyroidism: correlations with cardiometabolic biomarkers and risk factors. Endocrine. 2018;61 (1):83-93. PMID: 29455364. doi:10.1007/s12020-018-1550-3

33. Yurtdaş M, Asoğlu R, Özaydın A, Doğan Z. Lymphocyte to monocyte ratio may predict increased carotid intima-media thickness in patients with subclinical hypothyroidism. Clin Hemorheol Microcirc. 2021;77(2):133-142. PMID: 33074218. doi:10.3233/ $\mathrm{CH}-200820$ 
34. Zeng J, Xu Y, Shi Y, Jiang C. Inflammation role in sensory neuropathy in Chinese patients with diabetes/prediabetes. Clin Neurol Neurosurg. 2018;166:136-140. PMID: 29414152. doi:10.1016/j. clineuro.2018.01.031

35. Zheng H, Sun W, Zhang Q, et al. Proinflammatory cytokines predict the incidence of diabetic peripheral neuropathy over 5 years in Chinese type 2 diabetes patients: a prospective cohort study. EClinicalMedicine. 2020;31:100649. PMID: 33385123; PMCID: PMC7772538. doi:10.1016/j.eclinm.2020.100649

36. Srivastava VK, Singh H. Association of thyroid peroxidase antibody and dyslipidemia in subclinical hypothyroidism. J Family Med Prim Care. 2017;6(1):63-68. PMID: 29026751; PMCID: PMC5629902. doi:10.4103/2249-4863.214958

37. Goyal G, Goyal LD, Singla H, Sheenam AK, Kaur H. Subclinical hypothyroidism and associated cardiovascular risk factor in perimenopausal females. $J$ Midlife Health. 2020;11(1):6-11. PMID: 32684720; PMCID: PMC7362983. doi:10.4103/jmh.JMH 3819

38. Papanas N, Ziegler D. Risk factors and comorbidities in diabetic neuropathy: an update 2015. Rev Diabet Stud. 2015;12(1-2):48-62. PMID: 26676661; PMCID: PMC5397983. doi:10.1900/RDS.2015.12.48

39. Grisold A, Callaghan BC, Feldman EL. Mediators of diabetic neuropathy: is hyperglycemia the only culprit? Curr Opin Endocrinol Diabetes Obes. 2017;24(2):103-111. PMID: 28098594; PMCID: PMC5831542. doi:10.1097/MED.0000000000000320
40. Chahbi Z, Lahmar B, Hadri SE, et al. The prevalence of painful diabetic neuropathy in 300 Moroccan diabetics. Pan Afr Med J. 2018;31:158. PMID: 31086614; PMCID: PMC6488236. doi:10.11 604/pamj.2018.31.158.14687

41. Cho JH, Kim HJ, Lee JH, et al. Poor glycemic control is associated with the risk of subclinical hypothyroidism in patients with type 2 diabetes mellitus. Korean J Intern Med. 2016;31(4):703-711. PMID: 27271351; PMCID: PMC4939501. doi:10.3904/kjim.2015.198

42. Kocatürk E, Kar E, Küskü Kiraz Z, Alataş Ö. Insulin resistance and pancreatic $\beta$ cell dysfunction are associated with thyroid hormone functions: a cross-sectional hospital-based study in Turkey. Diabetes Metab Syndr. 2020;14(6):2147-2151. PMID: 33395774. doi:10.1016/ j.dsx.2020.11.008

43. British Thyroid Association. UK Guidelines for the Use of Thyroid Function Tests; 2006.

44. Ladenson PW, Singer PA, Ain KB, et al. American thyroid association guidelines for detection of thyroid dysfunction. Arch Intern Med. 2000;160(11):1573-1575. Erratum in: Arch Intern Med 2001 Jan 22;161(2):284. PMID: 10847249. doi:10.1001/archinte.160. 11.1573

45. Pearce SHS, Brabant G, Duntas LH, et al. 2013 ETA guideline: management of subclinical hypothyroidism. Eur Thyroid J. 2013;2 (4):215-228. PMID: 24783053; PMCID: PMC3923601. doi:10.1159/ 000356507
International Journal of General Medicine

\section{Publish your work in this journal}

The International Journal of General Medicine is an international, peer-reviewed open-access journal that focuses on general and internal medicine, pathogenesis, epidemiology, diagnosis, monitoring and treatment protocols. The journal is characterized by the rapid reporting of reviews, original research and clinical studies

\section{Dovepress}

across all disease areas. The manuscript management system is completely online and includes a very quick and fair peer-review system, which is all easy to use. Visit http://www.dovepress.com/ testimonials.php to read real quotes from published authors. 